length of time, cooling took place, an answer to which must await the work of Dr. Wiseman and his colleagues. There is evident need for further investigation of the extremes of climatic displacement which have resulted at various times in different parts of the world. The fact of the snow-line having been by no means uniformly lowered over the world as a whole, and the very variable length of the glacial phases, needs further study. The meteorologist is well capable of outlining pressure maps for the Ice Age; the importance now lies in the process by which transition was effected, and further evidence, from the field sciences, of the time required for such transitions may enable the meteorologist to provide an answer. The challenge of Mr. Hoyle's statement, that the change from Glacial to Climatic Optimum lies outside the operation of the earth's meteorological system, is one which will unquestionably stimulate further thought. Even the man of science on his Alpine holiday can reflect upon the conspicuous results of the seventy-odd years of decline of the Rhône glacier as a possible portent.

GORDON MANLeY

${ }^{1}$ Zeuner, F. E., "The Pleistocene Period", p. 250 (1945).

"Zeuner, F. E., "Dating the Past", 1st ed., p. 93 (1946). Florin, S., Geol. För. Stockholms Forh., 70, 17 (1948).

s Wiseman, J. D. H., Proc. Roy. Soc., A, 222, 296 (1954).

"Iversen, J., Science, 118, 9 (1953).

Ericson, D. B., Tech. Rep. Submarine Geol., No. 1, Lamont Geol. obs., 1 (1953).

-Ahlmann, H. W., "Glacier Variations and Climatic Fluctuations" (Bowman Lecture, No, 3) Amer. Geor. Soc. N.Y. (1953).

'Manley, G., Geogr. J., 117, 43 (1951). ${ }^{8}$ Discussion on Post-Glacial Climatic Change, Quart. J. Roy. Met. Soc.,

${ }^{9}$ Bowen, E. G., Aust. J. Phys., 6, No. 4, 490 (1953).

\section{NEW INSTITUTE OF CLINICAL SCIENCE AT THE QUEEN'S UNIVERSITY, BELFAST}

THE Institute of Clinical Science of the Belfast

Medical School was opened recently on behalf of the Duchess of Gloucester by Lord Wakehurst, the Governor of Northern Ireland. The purpose of the new Institute is to provide additional room for teaching and to increase the research facilities of the school. Owing to certain building restrictions, it was necessary to divide the building so that the Institute consists of two buildings united by a closed-in bridge.

The west block contains two large lecture theatres capable of seating 282 and 221. In these, special attention has been given to acoustics, and a very efficient and pleasing result has been obtained. They are mechanically ventilated and furnished with modern projection apparatus of various types. Tea,ching facilities are also supplied in eight tutorial rooms, each capable of seating thirty students, and furnished with projection and other apparatus for demonstration. The west block also contains the Departments of Therapeutics, Obstetrics and Gynæcology, Child Health and Social and Preventive Medicine, as well as a photographic unit and an artist's studio.

The Medical Library is also in the west block. It has been provided as a War memorial, and in addition to the main reading rooms has three separate reading rooms for undergraduates, postgraduates and staff, which serve as memorials to three young graduates who fell in the Second World War. These rooms are panclled in various woods, and the main room contains six paintings by Mr. Norman Wilkinson, depicting the counties of Northern Ireland. This building is linked to the Institute of Pathology and to the teaching wards of the Royal Victoria Hospital.

The east block contains the Departments of Medicine and Surgery. The third floor is designed for experimental research. Each member of staff has a private laboratory, while in addition each department has at least one communal laboratory. A great deal of thought has been given to the services for the whole building, and these are carried in the ceilings of the corridors; but they are readily accessible above the false ceilings and can be easily expanded to moct further developments. This distribution of the services renders maintenance a relatively easy matter.

The link with the hospital, and the provision of lifts, render it possible for a patient in bed to be wheeled to any floor for detailed investigation.

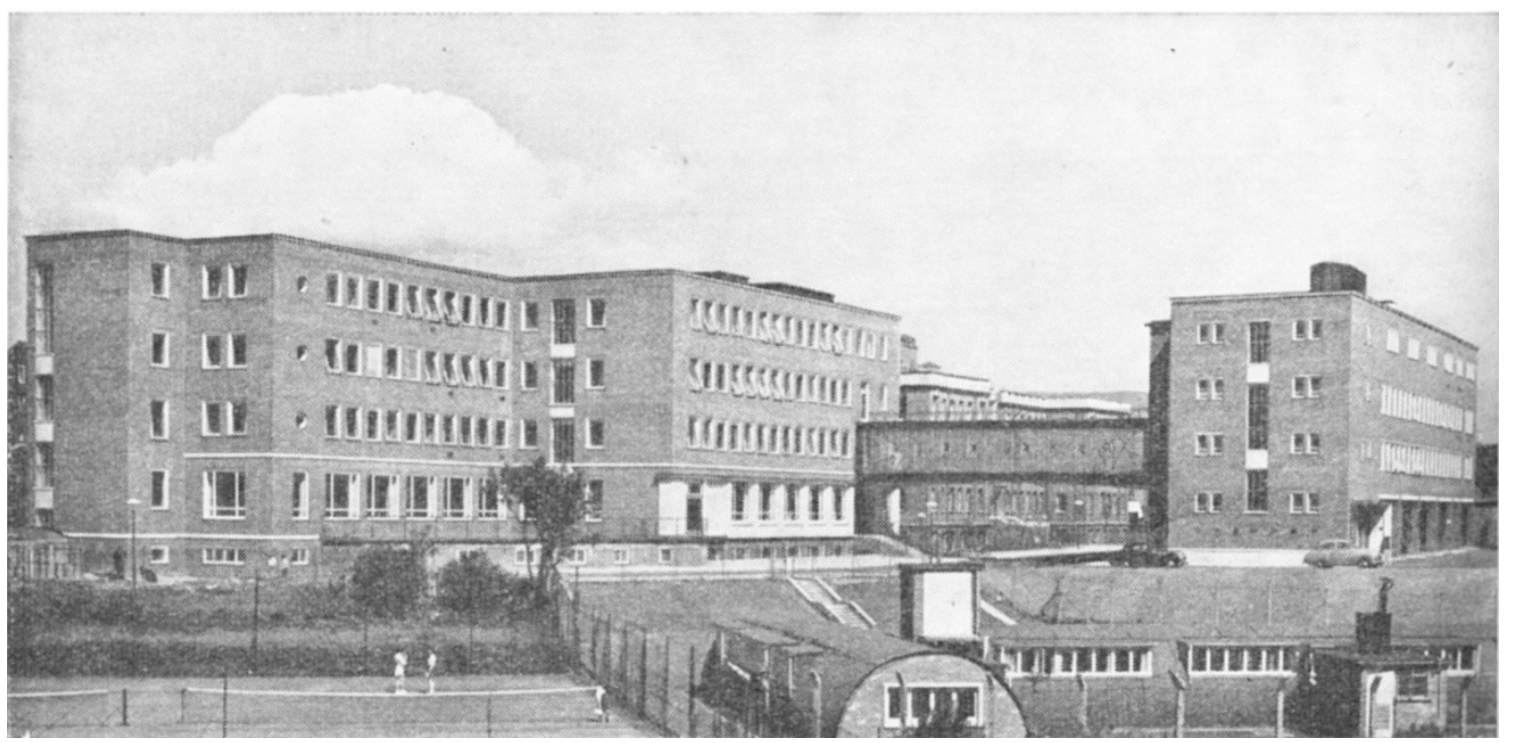


The architects have been successful in producing a pleasing exterior by using multicoloured Ravenhead russet brick and Portland stone. The windows, which are double for heat conservation, are in good proportion to the mass of the building. In all, the architects have succeeded in their aim and have provided a dignified building for the undergraduate, and excellent accommodation and facilities for the research work of the staff.

\section{THE TWO VISCOSITIES OF FLUIDS}

1 ROYAL SOCIETY discussion on "The First and Second Viscosities of Fluids" was held in the rooms of the Society, Burlington House, on April 29.

The discussion was opened by Prof. L. Rosenhead (Liverpool), who reviewed the fundamental facts and concepts. The generally assumed relationships between the stresses and rates of deformation in a homogeneous fluid lead to equations such as :

$$
\begin{gathered}
p_{x x}=-p+\mu^{\prime}\left(\frac{\partial u}{\partial x}+\frac{\partial v}{\partial y}+\frac{\partial w}{\partial z}\right)+2 \mu \frac{\partial u}{\partial x}, \\
p_{y z}=\mu\left(\frac{\partial v}{\partial z}+\frac{\partial w}{\partial y}\right),
\end{gathered}
$$

where $u, v$ and $w$ are the components of velocity referred to fixed orthogonal axes $O x, O y, O z ; p_{x x}$, $p_{y z}$ components of the stress tensor, $\mu$ the first (or shear) coefficient of viscosity and $\mu^{\prime}$ the second (or dilatational) coefficient of viscosity. The combination $\left(\mu^{\prime}+\frac{2}{3} \mu\right)$, denoted by $x$, is the bulk viscosity.

The physical meaning of $\mu$ is evident from equation (2), but that of $\mu^{\prime}$ depends on the interpretation of $p$ in equation (1). In the past the bulk viscosity has either been ignored, for which there is some justification if incompressible fluids are being considered, or it has been assumed to be zero, which is true if $p$ is equal to $-\left(p_{x x}+p_{y y}+p_{z z}\right) / 3$. If, how. ever, $p$ is not equal to this last expression, there is no a priori reason for assuming $x=0$, and its actual value (and hence the value of $\mu^{\prime}$ ) is open to experimental investigation for any given interpretation of $p$. Up to the present, the value of $x$ has not been measured directly, but values of $x / \mu$ have been deduced independently from the results of two different types of experiment-the absorption of sound-energy and the determination of the speed of acoustic streaming. In both cases $p$ is taken as the thermodynamic pressure, defined at constant entropy as a function of $p$. The former type of experiment is well established, but the latter field was opened up recently by the theory of Eckart ${ }^{1}$ and the experiments of Liebermann ${ }^{2}$. Liebermann concluded that there is reasonable agreement between values obtained by the two techniques. It was found that, at megacycle frequencies, $x / \mu$ is nearly zero for gases and liquefied gases, is 'small' (say 0-5) for bonded liquids, such as water and the alcohols, is larger $(5-20)$ for most organic liquids and largest for a group of nonpolar liquids including carbon tetrachloride, benzene and carbon disulphide. The last-named substance has the highest known value with $x / \mu=200$ at room temperatures.

These facts, however, merely provide a start, and a number of problems remain. From equations (1) and (2) it can be deduced that the sound absorption coefficient $\alpha$ is proportional to the square of the frequency. This is not always found (for example, with carbon disulphide and acetic acid), and deviations are often explained in terms of a 'relaxation' theory. What then is the significance to be attached to $p$ and $\mu^{\prime}$ in equation (1), and how is the theory of acoustic streaming to be modified? Further, there is some doubt about certain aspects of the technique employed by Liebermann for measuring the streaming velocities ; this is partly connected with questions of interpretation of results and partly with difficulties intrinsic in the technique.

Experimental questions concerning acoustic streaming were discussed by E. G. Richardson (Newcastle upon Tyne). He recalled that streaming was first recorded with sonic sources by Dvorák ${ }^{3}$ and afterwards investigated by Rayleigh ${ }^{4}$, Andrade ${ }^{5}$ and Schlichting ${ }^{6}$, who showed that at low frequencies the effect is due to vorticity generated in the boundary layer. Under these conditions recent experiments at Newcastle show that, if the termperature is varied, streaming appears to increase with decreasing viscosity. This also appears to remain true in the megacycle region, even for substances with large bulk viscosity. It was said that dissipative heating of the medium seems to be due to shear viscosity only, and that experiments on absorption of sound in capillaries can be explained in terms of the boundary effects, which are due only to shear viscosity. Richardson suggested that in view of the high vapour pressures of substances with large bulk viscosity, the possibility that cavitation plays a part in the streaming should be kept in mind. In connexion with this point, Prof. P. Biquard (Paris) remarked that, in order to investigate the effect of pressure and the possible effect of cavitation, he has experimented with various liquids at pressures up to about 100 atmospheres by measuring the scattering of light. The results show that absorption of energy under pressure can be accounted for quite simply by taking into account the percentage variation of viscosity with pressure. The question was also raised as to whether the absorption coefficient depends on the amplitude of the source and the hydrostatic pressure. The replies seemed to indicate that the reported measurements made with continuous waves, using pressure-vane techniques, do show a variation with amplitude, but those maple with pulsed waves do not. Increase of pressure has been observed to diminish the absorption in carbon tetrachloride and toluene; but this may be ascribed, in part, to changes in the first coefficient of viscosity and the velocity of sound, both of which enter into the Stokes absorption formula.

S. M. Karim (Karachi) mentioned the work he has recently carried out on the Liebermann type of experiment. He pointed out that the values obtained for $\mu^{\prime} / \mu$ sometimes appear to depend on the intensity of the sound beam, probably on account of the development of turbulence. Further, the choice of the ratio of the diameter of the sound beam to that. of the tube influences the experimental results. Additional detailed experimental work is required before firm conclusions can be drawn.

The difficulties of separating boundary layer effects from Eckart streaming were emphasized by P. E. Doak (Manchester), who went on to show how Eckart's original theory can be extended to deall with relaxing media while still neglecting boundary effects. He reached the conclusion that, apart from a term in the viscosity gradient, the streaming velocity is in all cases proportional to the coefficient 